\title{
Alternative dosing regimens for atezolizumab: an example of model-informed drug development in the postmarketing setting
}

\author{
Kari M. Morrissey ${ }^{1}$ (D) Mathilde Marchand ${ }^{2} \cdot$ Hina Patel $^{3} \cdot$ Rong Zhang $^{1} \cdot$ Benjamin $\mathrm{Wu}^{1} \cdot$ H. Phyllis Chan ${ }^{1}$. \\ Almut Mecke ${ }^{4}$ - Sandhya Girish ${ }^{1} \cdot \operatorname{Jin} Y$ Y. Jin ${ }^{1} \cdot$ Helen R. Winter ${ }^{1,6} \cdot$ René Bruno $^{5}$
}

Received: 6 June 2019 / Accepted: 3 September 2019 / Published online: 21 September 2019

(c) The Author(s) 2019

\begin{abstract}
Purpose To determine the exposure-response (ER) relationships between atezolizumab exposure and efficacy or safety in patients with advanced non-small cell lung cancer (NSCLC) or urothelial carcinoma (UC) and to identify alternative dosing regimens.

Methods ER analyses were conducted using pooled NSCLC and UC data from phase 1 and 3 studies (PCD4989g, OAK, IMvigor211; ClinicalTrials.gov IDs, NCT01375842, NCT02008227, and NCT02302807, respectively). Objective response rate, overall survival, and adverse events were evaluated vs pharmacokinetic (PK) metrics. Population PK-simulated exposures for regimens of $840 \mathrm{mg}$ every 2 weeks (q2w) and $1680 \mathrm{mg}$ every 4 weeks (q4w) were compared with the approved regimen of $1200 \mathrm{mg}$ every 3 weeks (q3w) and the maximum assessed dose (MAD; $20 \mathrm{mg} / \mathrm{kg} \mathrm{q} 3 \mathrm{w}$ ). Phase 3 IMpassion130 (NCT02425891) data were used to validate the PK simulations for $840 \mathrm{mg} \mathrm{q2w}$. Observed safety data were evaluated by exposure and body weight subgroups.

Results No significant ER relationships were observed for safety or efficacy. Predicted exposures for $840 \mathrm{mg}$ q2w and $1680 \mathrm{mg} \mathrm{q} 4 \mathrm{w}$ were comparable to $1200 \mathrm{mg} \mathrm{q} 3 \mathrm{w}$ and the MAD and consistent with observed PK data from IMpassion 130. Observed safety was similar between patients with a $C_{\max }$ above and below the predicted $C_{\max }$ for $1680 \mathrm{mg} \mathrm{q} 4 \mathrm{w}$ and between patients in the lowest and upper 3 body weight quartiles.

Conclusion Atezolizumab regimens of $840 \mathrm{mg} \mathrm{q} 2 \mathrm{w}$ and $1680 \mathrm{mg} \mathrm{q} 4 \mathrm{w}$ are expected to have comparable efficacy and safety as the approved regimen of $1200 \mathrm{mg} \mathrm{q} 3 \mathrm{w}$, supporting their interchangeable use and offering patients greater flexibility.
\end{abstract}

Keywords Atezolizumab PD-L1 · Population pharmacokinetics $\cdot$ Exposure-response

Electronic supplementary material The online version of this article (https://doi.org/10.1007/s00280-019-03954-8) contains supplementary material, which is available to authorized users.

Kari M. Morrissey

morrissey.kari@gene.com

1 Clinical Pharmacology, Genentech, Inc, 1 DNA Way, South San Francisco, CA 94080, USA

2 Certara Strategic Consulting, Certara, 54 Rue de Londres, 75009 Paris, France

3 Safety Science Oncology, Genentech Inc, 1 DNA Way, South San Francisco, CA 94080, USA

4 Biostatistics, F. Hoffmann-La Roche, Ltd, Hochstrasse 16, 4053 Basel, Switzerland

5 Clinical Pharmacology, Genentech/Roche, 84 Chemin des Grives, 13013 Marseille, France

6 Present Address: Seattle Genetics, 21717 30th Dr SE, Bothell, WA 98021, USA

\section{Introduction}

Immune checkpoint inhibition targeting programmed death-ligand 1 (PD-L1) or programmed death-1 (PD-1) has become an important approach in the treatment of multiple human cancers, as PD-L1 expression on tumor cells and tumor-infiltrating immune cells can inhibit anticancer immune responses [1]. Atezolizumab, a humanized, engineered monoclonal immunoglobulin (Ig) G1 antibody, selectively targets PD-L1 to block interactions with its receptors to promote T-cell activation and reinvigorate and enhance anticancer activity, while leaving the interaction between PD-L2 and PD-1 intact [1-3]. Atezolizumab is approved to treat certain types of locally advanced or metastatic non-small cell lung cancer (NSCLC) and urothelial carcinoma (UC) in the United States, Europe, and elsewhere, as well as locally advanced or metastatic 
triple-negative breast cancer (TNBC) and extensive-stage small-cell lung cancer (SCLC) in the United States $[4,5]$.

The first-in-human phase 1 dose-escalation and doseexpansion study PCD4989g evaluated atezolizumab monotherapy in patients with locally advanced or metastatic cancers using intravenous (IV) infusions of 0.01 to $20 \mathrm{mg} /$ $\mathrm{kg}$ doses every 3 weeks ( $\mathrm{q} 3 \mathrm{w}$ ) as well as a $1200 \mathrm{mg}$ flatdose equivalent of $15 \mathrm{mg} / \mathrm{kg} \mathrm{q} 3 \mathrm{w}$ [3]; no dose-limiting toxicities were observed, and no maximum tolerated dose was identified [3]. The pharmacokinetics (PK) of atezolizumab observed in this and subsequent clinical studies were consistent with the expected profile of an IgG1 antibody in humans, with a terminal half-life of 27 days [4, 6]. Atezolizumab demonstrated linear PK over the dose range of $1-20 \mathrm{mg} / \mathrm{kg}$ IV q3 $\mathrm{w}$, including the $1200 \mathrm{mg}$ dose. The clearance was $0.2 \mathrm{~L} /$ day, and the volume of distribution at steady state (achieved after 6-9 weeks of treatment) was $6.9 \mathrm{~L}$. Clearance was found to decrease with time (mean maximal reduction from baseline of approximately $17 \%)$, but this decrease did not appear to be clinically relevant [4]. Selection of the $1200 \mathrm{mg} \mathrm{q} 3 \mathrm{w}$ dosing regimen for further study was informed by nonclinical studies identifying a target serum exposure for atezolizumab [7] [minimum (trough) serum concentration $\left(C_{\min }\right)$ of $6 \mu \mathrm{g} /$ $\mathrm{mL}]$ and available PK and exposure-response (ER) data from several clinical studies, including PCD4989g and the pivotal phase 2 study IMvigor210 in locally advanced or metastatic UC, indicating that this target was achieved at $1200 \mathrm{mg} \mathrm{q} 3 \mathrm{w}$ for $>95 \%$ of patients [6].

The UC and NSCLC atezolizumab monotherapy indications, as well as the NSCLC and SCLC atezolizumab combination therapy indications, were first approved for IV infusions of $1200 \mathrm{mg} \mathrm{q} 3 \mathrm{w}$; the TNBC atezolizumab plus nab-paclitaxel combination indication was US Food and Drug Administration (FDA) approved at an atezolizumab dose of $840 \mathrm{mg}$ every 2 weeks (q2w). Identification of alternative dosing regimens that can be used interchangeably would offer patients greater convenience in their cancer treatment, particularly for combination regimens with diverse dosing requirements. The goals of this study were to determine the atezolizumab ER relationship for efficacy and safety and to apply this knowledge, along with population PK (popPK) simulations and the known safety profile of atezolizumab, to identify alternative dosing regimens. This "exposure-matching" approach to identify new dosing regimens is consistent with the model-informed drug development pilot programs endorsed by the FDA $[8,9]$, and these data have led to the expansion of the dosing regimens for several atezolizumab indications [4]. Accordingly, in May 2019, the $840 \mathrm{mg} \mathrm{q} 2 \mathrm{w}$ and $1680 \mathrm{mg} \mathrm{q} 4 \mathrm{w}$ dosing regimens were added to the FDA-approved UC, NSCLC and SCLC indications where atezolizumab is used as a single agent.

\section{Materials and methods}

\section{Studies}

Data from atezolizumab monotherapy studies, including the phase 1 study PCD4989g (NSCLC and UC cohorts only; ClinicalTrials.gov ID, NCT01375842) [3, 10-12] and phase 3 studies OAK (NSCLC, GO28915; ClinicalTrials.gov ID, NCT02008227) [13] and IMvigor211 (UC, GO29294; ClinicalTrials.gov ID, NCT02302807) [14] (Table S1), were used in the ER analyses based on clinical data cut-off dates of December 2, 2014; July 7, 2016; and March 13, 2017, respectively. OAK and IMvigor211, randomized studies of atezolizumab monotherapy vs chemotherapy, were used in tumor growth inhibition (TGI) modeling analyses. PK simulations were performed based on the popPK model [6] developed with Phase I data $(n=472)$ from PCD4989g and JO28944, the phase 1 study conducted in Japanese patients [15] and validated with data from over nine studies, including phase 3 studies OAK, IMvigor211, and IMpassion130 (WO29522; ClinicalTrials.gov ID, NCT02425891) [16]. Safety data for select patient subgroups from PCD4989g (using a data cut-off date of March 31, 2016) and OAK were summarized. The protocols for studies from which data were analyzed were approved by institutional review boards and/ or independent ethics committees at each site. All patients provided written informed consent.

\section{ER evaluations: measures, endpoints, and analyses}

ER analyses were performed to inform any relationships between PK metrics and ORR, OS, grade 3-5 adverse events (AEs), and AE of special interest (AESI) endpoints evaluated in previous clinical studies based on cycle 1 data to minimize potential bias due to both confounding with baseline prognostic factors $[17,18]$ and time-dependent variation in clearance that has been observed for atezolizumab and other checkpoint inhibitors [4, 8, 19-22]. These analyses were conducted using pooled data from atezolizumab-treated patients with NSCLC or UC (from PCD4989g, OAK, and IMvigor211) for whom exposure data were available, except as noted below for overall survival (OS). Exploratory ER analyses were performed using cycle 1 maximum serum concentration $\left(C_{\max }\right), C_{\min }$, and area under the concentration-time curve (AUC; time 0-21 days), as recommended [21] to minimize the effect of response-dependent time-varying clearance observed previously for anti-PD-1 and anti-PD-L1 agents [20]. AUC (time 0-21 days), $C_{\max }$, and $C_{\min }$ were derived at cycle 1 based on individual PK parameters estimated using cycle 
1 data only and the previously developed popPK model [6]. The efficacy endpoints evaluated were investigatorassessed confirmed Response Evaluation Criteria in Solid Tumors version 1.1 (RECIST 1.1) objective response rate (ORR; secondary endpoint in all studies) and OS (primary endpoint in OAK and IMvigor211). ORR analyses used data from atezolizumab-treated patients with NSCLC or UC in PCD4989g, OAK (first 850 randomized patients), and IMvigor211, whereas OS analyses used data from OAK (first 850 randomized patients) and IMvigor211 only. The safety endpoints evaluated included AEs of grades 3-5 per National Cancer Institute Common Terminology Criteria for Adverse Events version 4 and Medical Dictionary for Regulatory Activities version 20.1 (primary endpoint in PCD4989g, also evaluated in OAK and IMvigor211) and AESIs (evaluated in all studies). AESIs, conditions suggestive of autoimmune disorder, were defined previously [11].

ORR and AEs were evaluated as binary endpoints (yes/ no) and studied vs exposure as a continuous variable using logistic regression. The Wald test $P$ value was reported for each logistic regression, along with proportions/frequencies and their 95\% CIs computed for quartiles of exposure. For OS data, to mitigate confounding factors between patients' baseline information and atezolizumab clearance and exposure, TGI-OS modeling [23, 24] was performed. To be evaluable in this analysis (TGI evaluable), patients needed to have $\geq 1$ posttreatment sum of longest diameters (SLD) assessment. The impact of individual baseline prognostic factors and TGI metrics (estimated tumor shrinkage and tumor growth rates in a biexponential longitudinal model of the SLD of the target lesions per RECIST 1.1) on OS were explored using Kaplan-Meier and Cox regression analyses, and a parametric multivariate regression TGI-OS model was built. The final TGI-OS model was validated by simulation in its ability to describe OS distributions and hazard ratios (HRs) compared with a control in different subgroups (notably by exposure quartiles). For the HR simulations, TGI metric estimates and baseline covariates for control patients were taken from previous analyses [24, 25]. Exposure metrics were tested on the final multivariate model after adjustment for confounding with prognostic factors. A "tumor type" factor could be incorporated in the model if appropriate.

\section{PopPK simulations}

To simulate PK parameters of varying regimens of atezolizumab [840 mg q2w, $1200 \mathrm{mg} \mathrm{q} 3 \mathrm{w}, 1680 \mathrm{mg}$ every 4 weeks (q4w), and $20 \mathrm{mg} / \mathrm{kg} \mathrm{q} 3 \mathrm{w}$ ], Monte Carlo simulations were performed using the popPK model of atezolizumab, including covariate effects, previously developed using PCD4989g data [6] to obtain virtual individual PK profiles at cycle 1 and steady state. In the popPK model used for the PK simulations, bodyweight, albumin, tumor burden, treatmentemergent antidrug antibody (ADA) status, and gender were found to have a statistically significant impact on atezolizumab PK [6]. A single replicate of 500 patients was simulated for each regimen. A seed number was provided in the control stream to ensure reproducibility of the simulations. Random effects were sampled from the previously estimated distribution, and the residual error was not taken into account for individual predictions. Virtual patients per dosing regimen were assumed to have a 1:1 male:female ratio (males weighing $85 \mathrm{~kg}$ and females weighing $64 \mathrm{~kg}$, median body weight in the phase 1 database used to develop the popPK model). Other covariates affecting atezolizumab PK parameters were set to the median or most frequent category for the categorical covariates: albumin level of $40 \mathrm{~g} / \mathrm{L}$, baseline tumor size of $63 \mathrm{~mm}$, and negative for ADAs. Four dosing regimens were simulated: $1200 \mathrm{mg} \mathrm{q} 3 \mathrm{w}, 20 \mathrm{mg} / \mathrm{kg} \mathrm{q} 3 \mathrm{w}$ (i.e., $1700 \mathrm{mg}$ for males and $1280 \mathrm{mg}$ for females), $840 \mathrm{mg} \mathrm{q} 2 \mathrm{w}$, and $1680 \mathrm{mg} \mathrm{q} 4 \mathrm{w}$. To assess the impact of body weight on exposure after the fixed-dose regimen, 500 virtual patients per quartile of body weight with median albumin level, baseline tumor size, and negative for ADAs were assigned a dose of $840 \mathrm{mg} \mathrm{q} 2 \mathrm{w}$ or $1680 \mathrm{mg} \mathrm{q} 4 \mathrm{w}$. The distribution of body weight in the phase 1 population of patients was divided by quartiles as follows: 36.5-63.7, 63.7-77.0, 77.0-90.9, and $90.9-168.0 \mathrm{~kg}$. The 500 individual body weights were sampled in each quartile assuming a truncated normal distribution. To maintain the correlation between sex and body weight, the proportion of females was set to $80 \%$ in the first quartile, $50 \%$ in the second quartile, $25 \%$ in the third quartile, and $10 \%$ in the last quartile, as observed in the phase 1 database used to develop the popPK model.

Atezolizumab exposure metrics (cycle 1: AUC [calculated using the trapezoidal method; time 0-21 days], $C_{\max }$, and $C_{\min }$; steady state: AUC [dose/clearance], $C_{\max }$, and $C_{\min }$ ) were derived from the simulated individual PK profiles and summarized across individuals for each dosing regimen. To compare several dosing regimens involving different dosing intervals (every 2, 3, or 4 weeks), steady-state weekly AUC data were also derived.

\section{Validation of $840 \mathrm{mg}$ q2w exposure data from popPK predictions}

A prediction-corrected visual predictive check (pcVPC) was performed based on the prior phase 1 popPK model (external evaluation). The phase 1 popPK model was used to derive the individual PK parameter estimates based on atezolizumab observed concentration-time profiles in IMpassion130. PK data for atezolizumab-treated patients in IMpassion130 were simulated (1000 replicates) using actual dosing and patient covariates (body weight, sex, ADA status, albumin level, and tumor burden) and the phase 1 popPK 
model. Observed atezolizumab peak $\left(C_{\max }\right)$ and trough $\left(C_{\text {min }}\right)$ concentrations in IMpassion130 were compared with corresponding predictive distributions.

\section{Additional safety analyses}

$\mathrm{AE}$ frequencies were summarized for subgroups of patients: (1) from PCD4989g who received atezolizumab $20 \mathrm{mg} / \mathrm{kg}$ q3w based on $C_{\text {max }}$ values in relation to predicted $C_{\max }$ for the $1680 \mathrm{mg} \mathrm{q} 4 \mathrm{w}$ regimen, (2) from PCD4989g based on the atezolizumab dose received, and (3) from PCD4989g and OAK based on body weight quartiles (lowest quartile vs quartiles 2-4). In the PCD4989g study, adverse events were collected until 90 days following the last administration of study treatment or until initiation of the subsequent anticancer therapy, whichever occurred first (Figure S6, footnote 1). In these analyses, whether or not AESIs required the use of corticosteroids was also specified.

\section{Software}

Data set preparation, exploration, visualization, and analysis, including descriptive statistics, were performed using $\mathrm{R}$ version 3.4.3 and Comprehensive R Archive Network packages. Non-linear mixed-effect modeling using the first-order conditional estimation algorithm with interaction [Non-Linear Mixed-Effect Modeling tool (NONMEM) version 7.3; ICON Development Solutions, Ellicott City, MD, USA] [26] was

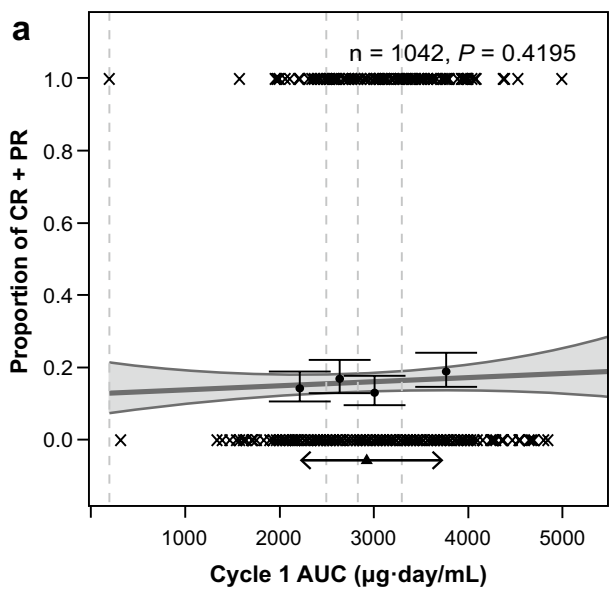

Fig. 1 Pooled exposure-response analyses of patients with locally advanced or metastatic NSCLC or UC. The proportions of responders are plotted vs (a) AUC or (b) $C_{\min }$ at cycle 1. In part (a), for legibility, 1 extreme AUC value ( $>15,000 \mu \mathrm{g}$.day $/ \mathrm{mL})$ is not displayed on the plot. Wald $P$ values from logistic regression of the proportion of responders vs exposure are displayed. Gray solid lines and shaded areas represent the logistic regression slope model and 95\% PI. Filled circles and error bars represent the proportions of responders in exposure quartiles and 95\% CI; vertical lines are the limits of the exposure quartiles. Cross markings $(\times)$ represent response events (0: no, used for Bayesian estimation of individual PK parameters. Logistic regression used the generalized linear model function in R with family "binomial" (variance = binomial; link $=\operatorname{logit}$ ). Monte Carlo PK simulations were implemented using NONMEM version 7.3, and simulation data sets to assess were created using $\mathrm{R}$.

\section{Results}

\section{Pooled ER analysis of efficacy}

Online resource Table S1 summarizes the patient populations and dosing regimens for the analyses in this study. A total of 164 of 1042 evaluable patients with exposure data (15.7\%) achieved a confirmed investigator-assessed ORR. No difference in ORR was observed between patients with NSCLC $(15.6 \%, n=501)$ or UC $(15.9 \%, n=541)$, so tumor type was not included in the logistic regression models. Neither AUC nor Cmin at cycle 1 was significantly related to the probability of response (Fig. 1).

For OS, a multivariate model was developed to account for baseline prognostic factors and TGI metrics. Median OS in OAK patients with NSCLC $[n=388$ TGI evaluable of 425 intention-to-treat (ITT) patients (91\%)] was 467 days (95\% CI 402-508 days) and in IMvigor211 patients with UC [ $n=382$ TGI evaluable of 467 ITT patients (82\%)] was 344 days (95\% CI 290-383 days). Based on this difference,

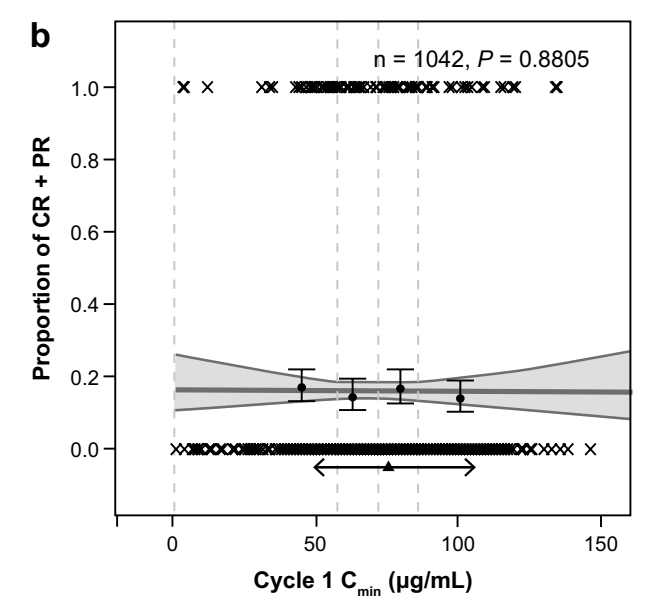

1: yes). Triangle and two-headed arrows represent the mean exposure and exposure interval between the 10th and 90th percentiles, respectively, for patients receiving atezolizumab $1200 \mathrm{mg}$ q3w. Cycle 1 AUC corresponds to the AUC during the first 3 weeks after treatment start and with PK parameters estimated based on cycle 1 data only. $A U C$ area under the concentration-time curve, $C_{\min }$ minimum (trough) serum atezolizumab concentration, $C R$ complete response, $n$ number of patients, NSCLC non-small cell lung cancer, $P I$ prediction interval, $P K$ pharmacokinetics, $P R$ partial response, $U C$ urothelial carcinoma 
tumor type was incorporated in the model. Of 770 TGIevaluable patients, 764 had exposure data. Individual estimates of $\log$ (tumor growth rate $[\mathrm{KG}]$ ) and baseline factors (e.g., Eastern Cooperative Oncology Group performance status $>0$; tumor size; albumin, lactate dehydrogenase, and alkaline phosphatase levels; PD-L1 status; and tumor type) were independent predictors of OS (Table S2). Of note, after accounting for baseline covariates in the final model, cycle 1 atezolizumab exposure (AUC, $C_{\min }$, or $C_{\max }$ ) was not significant $(P>0.01)$. The model performed well in simulating OS distribution and HRs by exposure quartiles for each tumor type even if exposure was not in the model. Comparisons of predicted and observed OS data are included in online resource Fig. S1 and Fig. S2. The flat ER relationship of atezolizumab was also illustrated in a simulation of the HRs by AUC quartiles after adjusting for baseline covariates (fixed to median values) and resampling KG as estimated (Fig. 2).

\section{Pooled ER analysis of safety}

Pooled atezolizumab exposure-safety analyses were performed on all atezolizumab-treated patients with locally advanced or metastatic NSCLC or UC with exposure data $(n=1228)$. AEs of grade $\geq 3$ and AESIs occurred in 209 (17.0\%) and $298(24.3 \%)$ of 1228 patients, respectively. AE frequencies were similar in patients with NSCLC compared with UC (14.9\% vs $19.6 \%$ for grade $\geq 3$ AEs; $24.6 \%$ vs $23.9 \%$ for AESIs); therefore, tumor type was not included in the logistic regression models. Neither safety analysis (incidence of grade $\geq 3$ AEs or AESIs) showed any statistically significant ER relationship with the cycle 1 exposure metrics, AUC and $C_{\max }$ (Fig. 3).

\section{PopPK prediction of atezolizumab exposure for various dosing regimens}

Simulated atezolizumab exposure profiles for four dosing regimens-1200 mg q3w, $840 \mathrm{mg} \mathrm{q} 2 \mathrm{w}, 1680 \mathrm{mg} \mathrm{q} 4 \mathrm{w}$, and $20 \mathrm{mg} / \mathrm{kg} \mathrm{q} 3 \mathrm{w}$ - are presented in Fig. 4. A summary of the exposure metrics associated with each dosing regimen is shown in Table 1.

For the $840 \mathrm{mg} \mathrm{q} 2 \mathrm{w}$ dosing regimen, the predicted $C_{\min }$ was $13 \%$ lower at cycle 1 and $16 \%$ higher at steady state than that for the $1200 \mathrm{mg} \mathrm{q} 3 \mathrm{w}$ dosing regimen and was also in excess of the $C_{\min }$ target concentration of $6 \mu \mathrm{g} / \mathrm{mL}$ [7] by $>$ tenfold. The $840 \mathrm{mg} \mathrm{q} 2 \mathrm{w}$ predicted $C_{\max }$ was lower than the $1200 \mathrm{mg} \mathrm{q} 3 \mathrm{w} C_{\max }$ at cycle 1 and steady state. For the $1680 \mathrm{mg} \mathrm{q} 4 \mathrm{w}$ dosing regimen, the predicted $C_{\min }$ was $14 \%$ higher at cycle 1 and $6 \%$ lower at steady state than that for the $1200 \mathrm{mg} \mathrm{q} 3 \mathrm{w}$ dosing regimen and was also in excess of the $C_{\min }$ target concentration of $6 \mu \mathrm{g} / \mathrm{mL}$ by $>$ tenfold. The $1680 \mathrm{mg} \mathrm{q} 4 \mathrm{w}$-predicted $C_{\max }$ was $12 \%$ higher at cycle 1 and $0.8 \%$ higher at steady state relative to the predicted

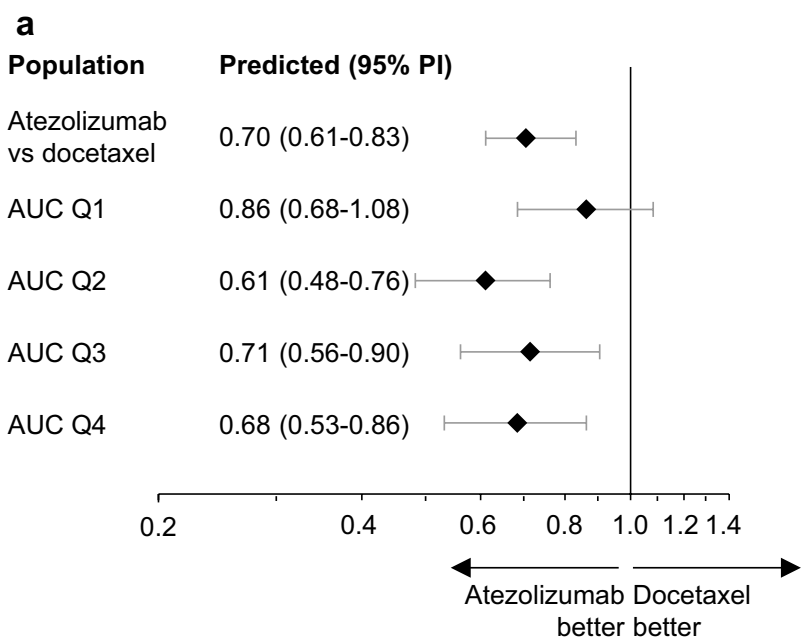

b

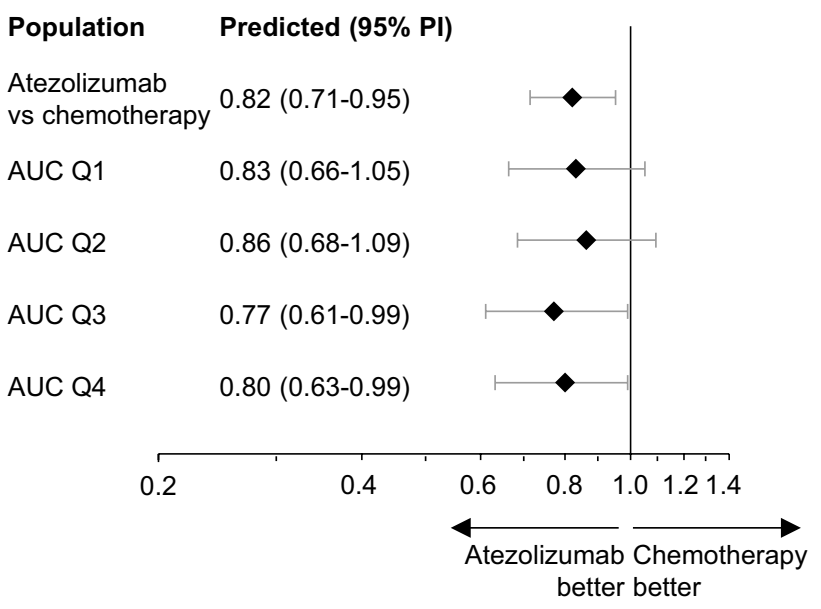

Fig. 2 Predicted OS HRs (atezolizumab vs comparator) by cycle 1 AUC quartiles for patients with median baseline covariates. Forest plots for OS HRs from (a) OAK (NSCLC) and (b) IMvigor211 (UC) are shown. Model-predicted HRs are shown as diamonds, with bars indicating 95\% PIs (1000 replicates). AUC area under the concentration-time curve, $H R$ hazard ratio, $N S C L C$ non-small cell lung cancer, $O S$ overall survival, $P I$ prediction interval, $U C$ urothelial carcinoma

geometric mean $C_{\max }$ for the $20 \mathrm{mg} / \mathrm{kg}$ dosing regimen, and was consistent with observed exposures for the $20 \mathrm{mg} / \mathrm{kg}$ q3w dosing regimen in PCD4989g [6, 27]. The predicted weekly AUC for the regimens of $840 \mathrm{mg} \mathrm{q} 2 \mathrm{w}$ and $1680 \mathrm{mg}$ $\mathrm{q} 4 \mathrm{w}$ at steady state were higher than those simulated for $1200 \mathrm{mg} \mathrm{q} 3 \mathrm{w}$ by $3.5 \%$ and $4.8 \%$, respectively.

When considering fixed-dose regimens, since clearance and volume are impacted by body weight in the atezolizumab popPK model [6], patients with lower body weight would be expected to exhibit higher atezolizumab exposure relative to heavier patients. To further evaluate the $\mathrm{q} 2 \mathrm{w}$ and q4w regimens, $C_{\min }$ or $C_{\max }$ was simulated by quartiles of body weight for dose levels of $840 \mathrm{mg} \mathrm{q} 2 \mathrm{w}$ and $1680 \mathrm{mg}$ $\mathrm{q} 4 \mathrm{w}$ (Table S3). For the $1680 \mathrm{mg} \mathrm{q} 4 \mathrm{w}$ regimen, the predicted 

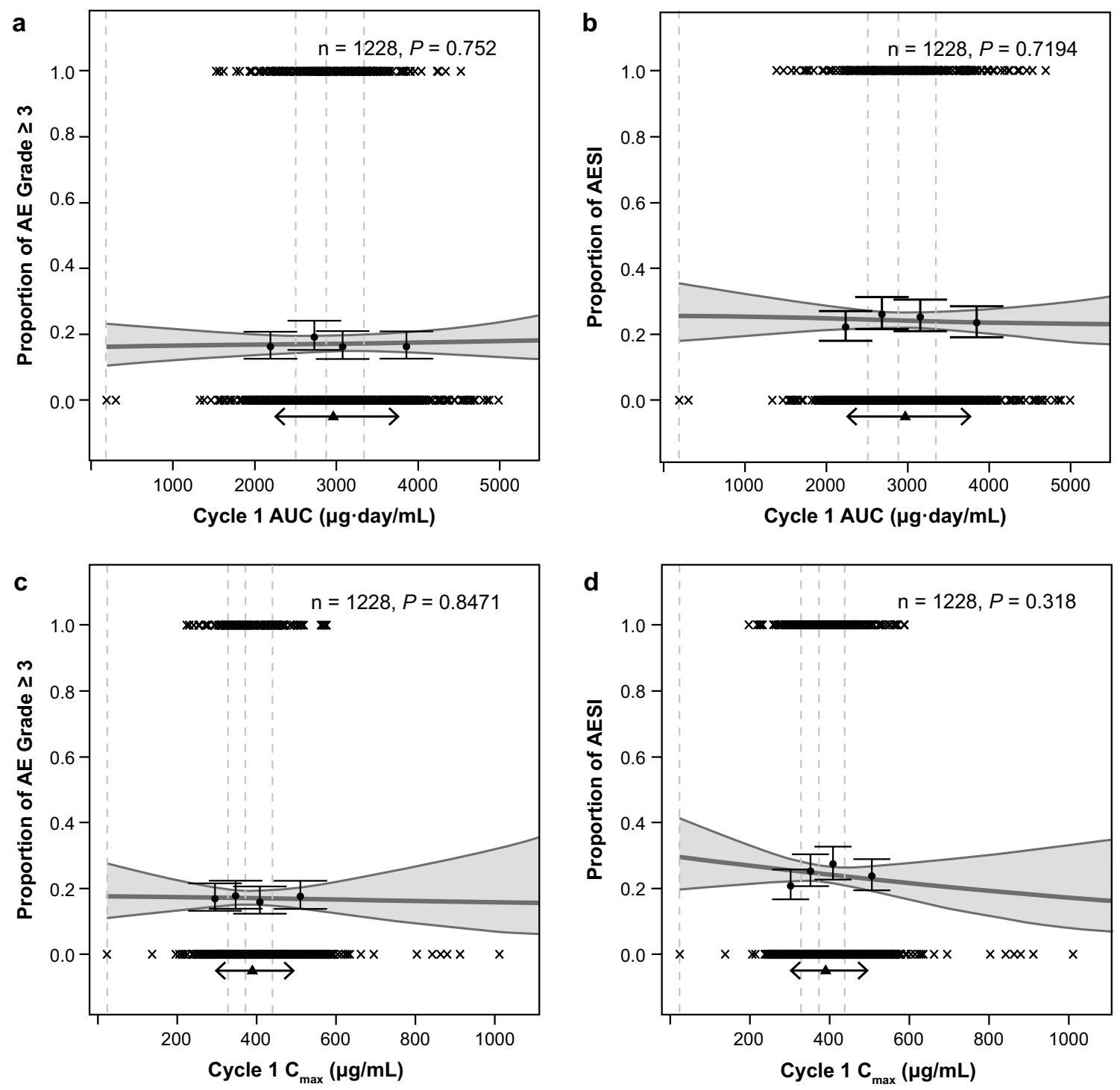

Fig. 3 Pooled exposure-response analyses of safety in patients with locally advanced or metastatic NSCLC or UC. Indicated AE frequencies ([a, c] grade $\geq 3$ AEs; $[\mathbf{b}, \mathbf{d}]$ AESIs) are plotted vs $(\mathbf{a}, \mathbf{b})$ AUC or $(\mathbf{c}, \mathbf{d}) C_{\max }$ at cycle 1 . For legibility, 2 extreme AUC values $(>15,000 \mu$ g.day $/ \mathrm{mL})$ and 2 extreme $C_{\max }$ values $(>1500 \mu \mathrm{g} / \mathrm{mL})$ are not displayed on the plots. Wald $P$ values from logistic regression of AE incidence vs exposure are displayed. Gray solid lines and shaded areas represent the logistic regression slope model and 95\% PI. Filled circles and error bars represent $\mathrm{AE}$ proportion in exposure quartiles and 95\% CI; vertical lines are the limits of the exposure quartiles.

$C_{\max }$ values for the lowest body weight quartile $(<63.7 \mathrm{~kg}$, with a majority of females) were 692 and $950 \mu \mathrm{g} / \mathrm{mL}$ for cycle 1 and steady state, respectively, which is within the range of the observed $C_{\max }$ values for $1200 \mathrm{mg} \mathrm{q} 3 \mathrm{w}$ and $20 \mathrm{mg} / \mathrm{kg} \mathrm{q} 3 \mathrm{w}[6,27]$. For the $840 \mathrm{mg} \mathrm{q} 2 \mathrm{w}$ regimen, the predicted $C_{\min }$ values for the highest body weight quartile (>90.9 kg, with a majority of males) were 58 and $158 \mu \mathrm{g} /$ $\mathrm{mL}$ for cycle 1 and steady state, respectively, which is within

Cross markings $(X)$ represent AE events (0: no, 1: yes). Triangle and two-headed arrows represent the mean exposure and exposure interval between the 10th and 90th percentiles, respectively, for patients receiving atezolizumab $1200 \mathrm{mg}$. Cycle 1 AUC corresponds to the AUC during the first 3 weeks after treatment start and with PK parameters estimated based on cycle 1 data only. $A E$ adverse event, $A E S I$ adverse event of special interest, $A U C$ area under the concentration-time curve, $C_{\max }$ maximum serum atezolizumab concentration, $n$ number of patients, NSCLC non-small cell lung cancer, $P I$ prediction interval, $P K$ pharmacokinetics, $U C$ urothelial carcinoma

the range of the observed $C_{\min }$ values for $1200 \mathrm{mg} \mathrm{q} 3 \mathrm{w}$ and above the $C_{\min }$ target concentration of $6 \mu \mathrm{g} / \mathrm{mL}$.

\section{Validation of popPK-predicted 840 mg q2w exposure}

As an external evaluation of phase 1 popPK model and to confirm the $840 \mathrm{mg} \mathrm{q} 2 \mathrm{w}$ PK simulations, the PK of the 

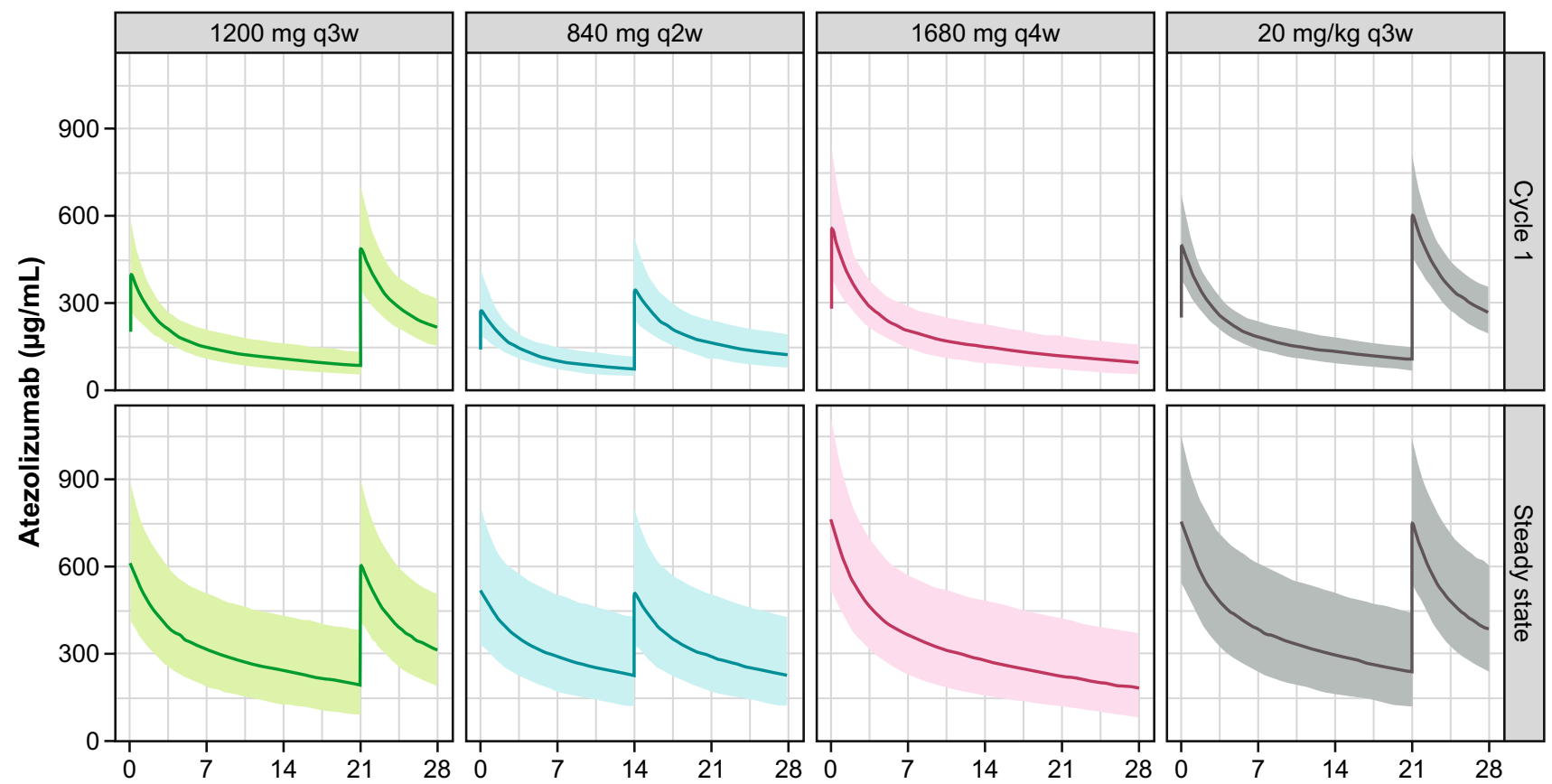

Time (days)

Fig. 4 Simulated atezolizumab exposure profiles for various dosing regimens. Geometric means are plotted. Shaded areas represent $90 \%$ PIs. PI prediction interval, $q 2 w$ every 2 weeks, $q 3 w$ every 3 weeks, $q 4 w$ every 4 weeks

Table 1 Summary statistics for atezolizumab exposure simulated for various regimens

\begin{tabular}{llcc}
\hline Regimen & $C_{\max }(90 \% \mathrm{PI}), \mu \mathrm{g} / \mathrm{mL}$ & $C_{\min }(90 \% \mathrm{PI}), \mu \mathrm{g} / \mathrm{mL}$ & $\begin{array}{c}\text { Weekly AUC }(90 \% \\
\mathrm{PI}), \mu \mathrm{g} \cdot \mathrm{day} / \mathrm{mL}^{\mathrm{a}}\end{array}$ \\
\hline $\begin{array}{l}1200 \mathrm{mg} \mathrm{q3w} \\
\text { Cycle 1 }\end{array}$ & $403(274-581)$ & $85(55-133)$ & $1048(763-1471)$ \\
Steady state & $610(414-891)$ & $194(89-383)$ & $2115(1264-3507)$ \\
840 mg q2w & & & \\
Cycle 1 & $281(187-420)$ & $226(118-426)$ & $2180(617-1237)$ \\
Steady state & $517(334-801)$ & & $1288(836-3733)$ \\
1680 mg q4w & & $97(58-159)$ & $2217(1357-3705)$ \\
Cycle 1 & $563(379-822)$ & $182(87-369)$ & $1305(1002-1683)$ \\
Steady state & $759(514-1106)$ & & $2596(1592-4140)$ \\
20 mg/kg q3w & & $107(70-149)$ & \\
Cycle 1 & $501(378-665)$ & $238(115-443)$ & \\
Steady state & $753(544-1038)$ & & \\
\hline
\end{tabular}

Geometric means with $90 \%$ PIs (for 500 patients) are shown

$A U C$ area under the concentration-time curve, $C_{\max }$ maximum serum atezolizumab concentration, $C_{\min }$ minimum (trough) serum atezolizumab concentration, $P I$ prediction interval, $q 2 w$ every 2 weeks, $q 3 w$ every 3 weeks, $q 4 w$ every 4 weeks

${ }^{\mathrm{a}}$ Weekly AUC over 3 weeks (for $\mathrm{q} 3 \mathrm{w}$ regimens), over 4 weeks (for $\mathrm{q} 4 \mathrm{w}$ regimen), and over 2 weeks (for $\mathrm{q} 2 \mathrm{w}$ regimen)

atezolizumab plus nab-paclitaxel $\mathrm{q} 2 \mathrm{w}$ arm from the IMpassion130 study were simulated based on baseline patient covariates (pcVPC). Four-hundred forty-three (of 445) atezolizumab-treated patients had evaluable serum samples for PK analysis, for a total of 2232 samples. Results are presented in Fig. 5. Both dose 1 and steady-state exposure metrics were similar to those predicted for the $840 \mathrm{mg} \mathrm{q} 2 \mathrm{w}$ dosing regimen based on the phase 1 popPK model. A trend toward underprediction of the median and fifth percentile of atezolizumab exposure data (troughs) after longer-term 


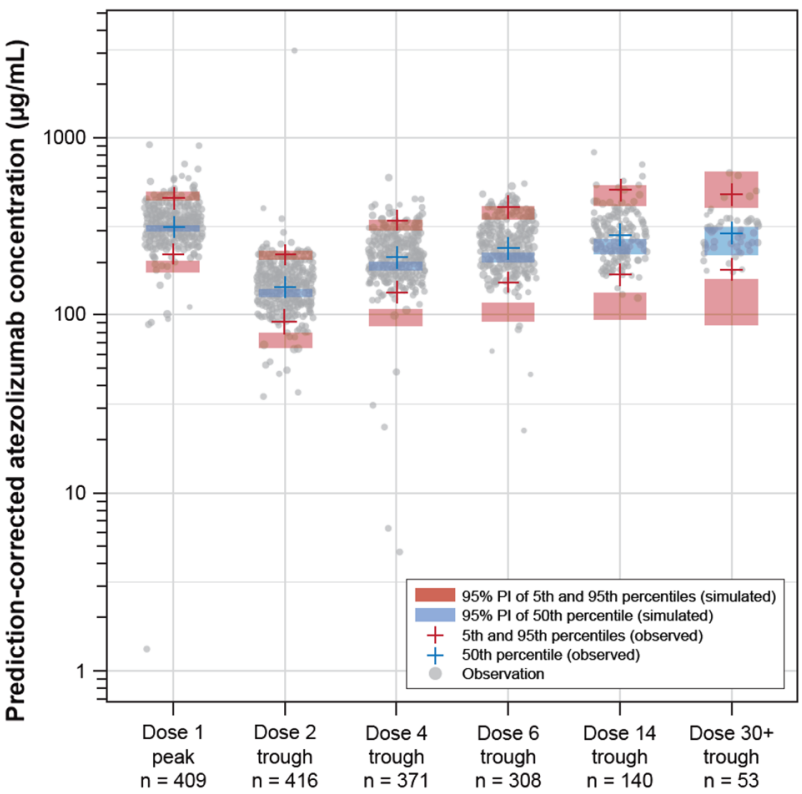

Fig. 5 Prediction-corrected VPC of atezolizumab data in TNBC (IMpassion130) using the phase 1 popPK model. Data are plotted on a semi-log scale. Two population-predicted concentrations $<1 \mu \mathrm{g} /$ $\mathrm{mL}$ are not displayed on this plot. $n$ number of samples, $P I$ prediction interval, popPK population pharmacokinetics, $T N B C$ triple-negative breast cancer, $V P C$ visual performance check

administration (doses 2, 4, 6, 14, and 30+) was observed for the popPK model, consistent with the time-dependent clearance of atezolizumab [4].

\section{Safety by $C_{\max }$ relative to that predicted for $1680 \mathrm{mg}$ q4w}

Table S4 provides a safety summary for $20 \mathrm{mg} / \mathrm{kg} \mathrm{q} 3 \mathrm{w}$ atezolizumab-treated patients in PCD4989g, with observed $C_{\max }$ during cycle 1 relative to the mean predicted $C_{\max }$ of the $1680 \mathrm{mg} \mathrm{q} 4 \mathrm{w}$ regimen. In general, $\mathrm{AE}$ frequencies were similar between these groups. Similar results were obtained in groups based on the PCD4989g patients' modeled $C_{\max }$ (i.e., individual predictions estimated by the popPK model) relative to the mean predicted $C_{\max }$ of the $1680 \mathrm{mg} \mathrm{q} 4 \mathrm{w}$ regimen.

\section{Safety by dose group}

Table S5 provides a summary of atezolizumab exposure by dose group. In a dose range from $10 \mathrm{mg} / \mathrm{kg} \mathrm{q} 3 \mathrm{w}$ to $20 \mathrm{mg} /$ $\mathrm{kg} \mathrm{q} 3 \mathrm{w}$ and $1200 \mathrm{mg} \mathrm{q} 3 \mathrm{w}$, the median treatment duration ranged from 2.07 to 9.48 months, and the median number of doses ranged from 4 to 14.5. Table S6 provides a safety summary for PCD4989g patients by dose group. The overall safety profile was consistent among the $15 \mathrm{mg} / \mathrm{kg} \mathrm{q} 3 \mathrm{w}$, $20 \mathrm{mg} / \mathrm{kg} \mathrm{q} 3 \mathrm{w}$, and $1200 \mathrm{mg} \mathrm{q} 3 \mathrm{w}$ dose groups. Patients in the $10 \mathrm{mg} / \mathrm{kg}$ q3w dose group demonstrated increased frequency of serious AEs and treatment-related AEs relative to the other dose groups. This may be due to the longer safety follow-up and the lower number of patients in this dose group relative to the other dose groups.

\section{Safety by body weight}

Table S7 provides a safety summary for PCD4989g and OAK patients by body weight. Median body weight in the $20 \mathrm{mg} / \mathrm{kg}$ treatment group in PCD4989g was $78.2 \mathrm{~kg}$ (Q1-Q3, 63.7-93.0 kg), and the overall safety profile was generally similar between patients in the lowest $(n=37)$ and upper $3(n=109)$ body weight quartiles. A higher incidence of grade 3-5 AEs (48.7\% vs 37.3\%) in the lowest body weight quartile subgroup was observed, which was due to grade $3 \mathrm{AEs}(38.8 \%$ vs $27.8 \%$ ). Evaluation of grade 3 AEs did not identify any individual AE preferred term with $a \geq 2 \%$ difference between subgroups. Serious AEs with a $\geq 5 \%$ difference between subgroups included fatigue and asthenia (both common to malignancy) as well as pneumonia and cardiac tamponade (known complications of thoracic cancers), with all such events occurring infrequently. In the lowest body weight subgroup, only asthenia and respiratory complications led to study treatment withdrawal; no action with respect to study treatment was taken for the other events. To assess the impact of body weight in a larger cohort of patients, AE data from OAK (1200 mg q3w dosing) were also analyzed. Median body weight was $71.0 \mathrm{~kg}$ (Q1-Q3, 59.5-82.2 kg). No differences between the lowest $(n=152)$ and upper $3(n=442)$ body weight quartiles were observed.

\section{Discussion}

Results from this study support the interchangeable use of $840 \mathrm{mg} \mathrm{q} 2 \mathrm{w}, 1200 \mathrm{mg} \mathrm{q} 3 \mathrm{w}$, and $1680 \mathrm{mg} \mathrm{q} 4 \mathrm{w}$ dosing regimens for atezolizumab, as they are anticipated to demonstrate comparable efficacy and safety profiles while offering patients greater flexibility and convenience in their treatment. Briefly, data from all evaluated dose levels using a $\mathrm{q} 3 \mathrm{w}$ dosing frequency, including $1200 \mathrm{mg} \mathrm{q} 3 \mathrm{w}$ and $20 \mathrm{mg} /$ $\mathrm{kg} \mathrm{q3}$ w (the MAD in the phase 1 study PCD4989g), demonstrated that there was not a clinically meaningful exposure-efficacy or exposure-safety relationship. These data suggest that if a new dosing regimen achieves an exposure within the observed exposure range for $1200 \mathrm{mg}$ q3w or $20 \mathrm{mg} / \mathrm{kg} \mathrm{q} 3 \mathrm{w}$, it is not likely to impact efficacy or safety. PK simulations suggested that the new dosing regimens, $840 \mathrm{mg}$ $\mathrm{q} 2 \mathrm{w}$ and $1680 \mathrm{mg} \mathrm{q} 4 \mathrm{w}$, are predicted to achieve generally comparable exposure to that of the currently approved regimen of $1200 \mathrm{mg} \mathrm{q} 3 \mathrm{w}$ and are within the range of observed 
exposures from the $1200 \mathrm{mg} \mathrm{q} 3 \mathrm{w}$ and $20 \mathrm{mg} / \mathrm{kg}$ dose levels. Further characterization of the observed safety profile of patients with a $C_{\max }$ above and below the predicted $C_{\max }$ of the $1680 \mathrm{mg} \mathrm{q} 4 \mathrm{w}$ regimen also supports that the safety profile of $1680 \mathrm{mg} \mathrm{q} 4 \mathrm{w}$ is anticipated to be similar to the clinical experience with the $\mathrm{q} 3 \mathrm{w}$ regimen.

Several studies of atezolizumab combination regimens have implemented $840 \mathrm{mg} \mathrm{q} 2 \mathrm{w}$ dosing to be more compatible with the dosing schedule of combination agents, including the phase 3 study IMpassion130 [16]. Our popPK model simulations of an $840 \mathrm{mg} \mathrm{q} 2 \mathrm{w}$ regimen indicated that this dosing achieved comparable overall exposure to that of the $1200 \mathrm{mg} \mathrm{q} 3 \mathrm{w}$ regimen; the $C_{\max }$ and $C_{\min }$ values were within the observed $1200 \mathrm{mg}$ q $3 \mathrm{w}$ range, with the predicted $C_{\min }$ exceeding the target concentration of $6 \mu \mathrm{g} / \mathrm{mL}$ by at least tenfold. When applying the phase 1 popPK model to simulate IMpassion 130 data, the pcVPC suggested adequate model performance for the median cycle $1 C_{\max }$. A trend toward underprediction of the median and fifth percentile of atezolizumab exposure was observed after long-term treatment, consistent with the aforementioned observations of time-dependent decreases in atezolizumab clearance over time [4]

The PK simulations of a $1680 \mathrm{mg} \mathrm{q} 4 \mathrm{w}$ dosing regimen (equivalent to a $21 \mathrm{mg} / \mathrm{kg}$ q $3 \mathrm{w}$ dosing regimen for an $80-\mathrm{kg}$ patient) also indicated comparable overall exposure to the currently approved regimen of $1200 \mathrm{mg} \mathrm{q} 3 \mathrm{w}$, while the predicted steady-state $C_{\min }$ was $6 \%$ lower than that for the currently approved regimen; this concentration also exceeded the target concentration. A small increase in cycle 1 and steady-state geometric mean $C_{\max }(12 \%$ and $0.8 \%$, respectively) was anticipated when compared with the $20 \mathrm{mg} / \mathrm{kg}$ dose; however, the predicted $C_{\max }$ for the $1680 \mathrm{mg} \mathrm{q} 4 \mathrm{w}$ regimen was within the range observed in the phase 1 study PCD4989g. Further, patients from PCD4989g treated at $20 \mathrm{mg} / \mathrm{kg}$ q3w had comparable safety regardless of whether their $C_{\max }$ was above or below the predicted cycle 1 values for the $1680 \mathrm{mg} \mathrm{q} 4 \mathrm{w}$ regimen.

Similar to observations with the $1200 \mathrm{mg} \mathrm{q} 3 \mathrm{w}$ regimen [6], the impact of body weight on exposure is not anticipated to be clinically meaningful for the $840 \mathrm{mg} \mathrm{q} 2 \mathrm{w}$ or $1680 \mathrm{mg}$ $\mathrm{q} 4 \mathrm{w}$ regimens, as the predicted exposures for patients with low and high body weight are within range of observed exposures from the $1200 \mathrm{mg} \mathrm{q} 3 \mathrm{w}$ and $20 \mathrm{mg} / \mathrm{kg}$ dose levels. These results are also further supported by a safety analysis from studies PCD4989g and OAK by body weight, which demonstrated that the overall observed safety profile was generally similar between patients in the lowest and upper 3 body weight quartiles.

The maintenance of consistent $C_{\min }$ levels of a protein therapeutic is considered to not only provide the most consistent disease control but also to minimize the likelihood of development of ADAs. Clinical data from TNF inhibitor studies show that episodic exposure to a protein therapeutic (i.e., exposure followed by complete washout, followed by re-exposure) is more likely to induce an immune response than the consistent presence of the same protein at the same level $[28,29]$. The predicted $C_{\min }$ levels of the $840 \mathrm{mg} \mathrm{q} 2 \mathrm{w}$ and $1680 \mathrm{mg} \mathrm{q} 4 \mathrm{w}$ regimens are well in excess of the target concentration $(6 \mu \mathrm{g} / \mathrm{mL})$ and are within range of $C_{\min }$ values of the approved $1200 \mathrm{mg} \mathrm{q} 3 \mathrm{w}$ regimen. Therefore, it is not anticipated that the $840 \mathrm{mg} \mathrm{q} 2 \mathrm{w}$ or $1680 \mathrm{mg} \mathrm{q} 4 \mathrm{w}$ regimens would result in a complete washout and re-exposure cycle that would lead to a higher immunogenicity rate than the approved $1200 \mathrm{mg} \mathrm{q} 3 \mathrm{w}$ regimen.

The ability to administer atezolizumab at a less frequent dosing regimen (i.e., $1680 \mathrm{mg} \mathrm{q} 4 \mathrm{w}$ ) provides patients, caregivers, and healthcare providers greater flexibility and convenience. As atezolizumab is administered intravenously, the $1680 \mathrm{mg} \mathrm{q} 4 \mathrm{w}$ dosing regimen is likely to reduce the time needed to receive treatment (e.g., number of visits to treatment centers) relative to a regimen dosed more frequently. In addition, the ability to switch regimens throughout treatment will also allow for greater flexibility as the dosing schedule can be matched to meet the evolving needs of each individual patient. Related approaches allowing patients and providers the option to choose between several dosing frequencies have also been applied to other checkpoint inhibitors indicated in some tumor types [8,30-34].

Atezolizumab regimens of $840 \mathrm{mg} \mathrm{q} 2 \mathrm{w}$ and $1680 \mathrm{mg} \mathrm{q} 4 \mathrm{w}$ are expected to have comparable efficacy and safety to the approved regimen of $1200 \mathrm{mg} \mathrm{q} 3 \mathrm{w}$, given that the predicted exposures are within the range of observed exposures and there is no clinically meaningful ER relationship. Further, as atezolizumab PKs are consistent between indications and in combination with various agents evaluated (including, but not limited to, chemotherapy, antineoplastic drugs, and tyrosine kinase inhibitors), these results are applicable across indications where atezolizumab is administered either as monotherapy or in combination. This modeling and simulation approach, whereby new dosing regimens are identified through "exposure matching" and supported by the ER relationship and observed safety across dose levels, is in line with the model-informed drug development pilot programs endorsed by the FDA [8, 9]. In summary, this analysis supports the interchangeable use of atezolizumab dosing regimens of $840 \mathrm{mg} \mathrm{q} 2 \mathrm{w}, 1200 \mathrm{mg} \mathrm{q} 3 \mathrm{w}$, and $1680 \mathrm{mg} \mathrm{q} 4 \mathrm{w}$, offering patients greater flexibility and convenience during their atezolizumab treatment. These data contributed to the expansion of atezolizumab dosing regimens for certain types of cancers by the FDA [4].

Acknowledgements The authors thank Vilma Graupner, PhD (F. Hoffmann-La Roche, Ltd.), for her contributions to the study; Julia Suchomel, BS (Genentech, Inc.), for technical expertise and careful review of the manuscript; and Nitzan Sternheim, PhD (Genentech, Inc.), for her strategic guidance and support of this work. The authors 
also thank Valerie Quarmby, PhD, and Jane Ruppel (Genentech, Inc.) for their technical expertise and Professors Achim Rittmeyer, MD (Lungenfachklinik Immenhausen), and Thomas Powles, MD (Barts Cancer Institute), for their medical expertise and critical review of the manuscript. The authors are deeply indebted to Laurent Claret, $\mathrm{PhD}$ (Genentech, Inc.), who developed the methodology and analysis codes for TGI-OS modeling. Medical writing assistance for this manuscript was provided by Ashley J. Pratt, PhD, of Health Interactions and funded by F. Hoffmann-La Roche, Ltd.

Funding This study was sponsored by F. Hoffmann-La Roche, Ltd.

\section{Compliance with ethical standards}

Conflict of interest K.M. Morrissey, H. Patel, R. Zhang, B. Wu, H.P. Chan, S. Girish, J.Y. Jin, H.R. Winter, and R. Bruno are employed by Genentech, Inc. M. Marchand is employed by Certara Strategic Consulting. A. Mecke is employed by F. Hoffmann-La Roche, Ltd.

Ethical approval All procedures performed in studies involving human participants were in accordance with the ethical standards of the institutional and/or national research committees and with the 1964 Helsinki Declaration and its later amendments or comparable ethical standards. This article does not contain any studies with animals performed by any of the authors.

Data sharing Qualified researchers may request access to individual patient-level data through the clinical study data request platform (www.clinicalstudydatarequest.com). Further details on Roche's criteria for eligible studies are available here (https://clinicalstudydatareq uest.com/Study-Sponsors/Study-Sponsors-Roche.aspx). For further details on Roche's Global Policy on the Sharing of Clinical Information and how to request access to related clinical study documents, see here (https://www.roche.com/research_and_development/who_we_are_ how_we_work/clinical_trials/our_commitment_to_data_sharing.htm).

Open Access This article is distributed under the terms of the Creative Commons Attribution 4.0 International License (http://creativeco mmons.org/licenses/by/4.0/), which permits unrestricted use, distribution, and reproduction in any medium, provided you give appropriate credit to the original author(s) and the source, provide a link to the Creative Commons license, and indicate if changes were made.

\section{References}

1. Chen DS, Mellman I (2013) Oncology meets immunology: the cancer-immunity cycle. Immunity 39(1):1-10. https://doi. org/10.1016/j.immuni.2013.07.012

2. Chen DS, Irving BA, Hodi FS (2012) Molecular pathways: nextgeneration immunotherapy-inhibiting programmed death-ligand 1 and programmed death-1. Clin Cancer Res 18(24):6580-6587. https://doi.org/10.1158/1078-0432.CCR-12-1362

3. Herbst RS, Soria JC, Kowanetz M, Fine GD, Hamid O, Gordon MS, Sosman JA, McDermott DF, Powderly JD, Gettinger SN, Kohrt HE, Horn L, Lawrence DP, Rost S, Leabman M, Xiao Y, Mokatrin A, Koeppen H, Hegde PS, Mellman I, Chen DS, Hodi FS (2014) Predictive correlates of response to the anti-PD-L1 antibody MPDL3280A in cancer patients. Nature 515(7528):563-567. https://doi.org/10.1038/nature14011

4. TECENTRIQ (atezolizumab) [package insert]. Genentech, Inc, South San Francisco, 2019
5. TECENTRIQ (atezolizumab) [summary of product characteristics]. Roche Registration Limited, Welwyn Garden City, 2019

6. Stroh M, Winter H, Marchand M, Claret L, Eppler S, Ruppel J, Abidoye O, Teng SL, Lin WT, Dayog S, Bruno R, Jin J, Girish S (2017) Clinical pharmacokinetics and pharmacodynamics of atezolizumab in metastatic urothelial carcinoma. Clin Pharmacol Ther 102(2):305-312. https://doi.org/10.1002/cpt.587

7. Deng R, Bumbaca D, Pastuskovas CV, Boswell CA, West D, Cowan KJ, Chiu H, McBride J, Johnson C, Xin Y, Koeppen H, Leabman M, Iyer S (2016) Preclinical pharmacokinetics, pharmacodynamics, tissue distribution, and tumor penetration of anti-PDL1 monoclonal antibody, an immune checkpoint inhibitor. MAbs 8(3):593-603. https://doi.org/10.1080/19420862.2015.1136043

8. Bi Y, Liu J, Furmanski B, Zhao H, Yu J, Osgood C, Ward A, Keegan P, Booth BP, Rahman A, Wang Y (2019) Model-informed drug development approach supporting approval of the 4-week (Q4W) dosing schedule for nivolumab (Opdivo) across multiple indications: a regulatory perspective. Ann Oncol 30(4):644-651. https://doi.org/10.1093/annonc/mdz037

9. US Food and Drug Administration. (2019) Model-informed drug development pilot program. https://www.fda.gov/drugs/devel opment-resources/model-informed-drug-development-pilot-progr am. Accessed 14 May 2019

10. Powles T, Eder JP, Fine GD, Braiteh FS, Loriot Y, Cruz C, Bellmunt J, Burris HA, Petrylak DP, Teng SL, Shen X, Boyd Z, Hegde PS, Chen DS, Vogelzang NJ (2014) MPDL3280A (anti-PD-L1) treatment leads to clinical activity in metastatic bladder cancer. Nature 515(7528):558-562. https://doi.org/10.1038/nature13904

11. Petrylak DP, Powles T, Bellmunt J, Braiteh F, Loriot Y, MoralesBarrera R, Burris HA, Kim JW, Ding B, Kaiser C, Fasso M, O'Hear C, Vogelzang NJ (2018) Atezolizumab (MPDL3280A) monotherapy for patients with metastatic urothelial cancer: longterm outcomes from a phase 1 study. JAMA Oncol 4(4):537-544. https://doi.org/10.1001/jamaoncol.2017.5440

12. Horn L, Gettinger SN, Gordon MS, Herbst RS, Gandhi L, Felip E, Sequist LV, Spigel DR, Antonia SJ, Balmanoukian A, Cassier PA, Liu B, Kowanetz M, O'Hear C, Fassò M, Grossman W, Sandler A, Soria JC (2018) Safety and clinical activity of atezolizumab monotherapy in metastatic non-small-cell lung cancer: final results from a phase I study. Eur J Cancer 101:201-209. https:// doi.org/10.1016/j.ejca.2018.06.031

13. Rittmeyer A, Barlesi F, Waterkamp D, Park K, Ciardiello F, von Pawel J, Gadgeel SM, Hida T, Kowalski DM, Dols MC, Cortinovis DL, Leach J, Polikoff J, Barrios C, Kabbinavar F, Frontera OA, De Marinis F, Turna H, Lee JS, Ballinger M, Kowanetz M, He P, Chen DS, Sandler A, Gandara DR, Group OAKS (2017) Atezolizumab versus docetaxel in patients with previously treated non-small-cell lung cancer (OAK): a phase 3, open-label, multicentre randomised controlled trial. Lancet (Lond, Engl) 389(10066):255-265

14. Powles T, Duran I, van der Heijden MS, Loriot Y, Vogelzang NJ, De Giorgi U, Oudard S, Retz MM, Castellano D, Bamias A, Flechon A, Gravis G, Hussain S, Takano T, Leng N, Kadel EE 3rd, Banchereau R, Hegde PS, Mariathasan S, Cui N, Shen X, Derleth CL, Green MC, Ravaud A (2018) Atezolizumab versus chemotherapy in patients with platinum-treated locally advanced or metastatic urothelial carcinoma (IMvigor211): a multicentre, open-label, phase 3 randomised controlled trial. Lancet (Lond, Engl) 391(10122):748-757

15. Mizugaki H, Yamamoto N, Murakami H, Kenmotsu H, Fujiwara Y, Ishida Y, Kawakami T, Takahashi T (2016) Phase I dosefinding study of monotherapy with atezolizumab, an engineered immunoglobulin monoclonal antibody targeting PD-L1, in Japanese patients with advanced solid tumors. Invest New Drugs 34(5):596-603. https://doi.org/10.1007/s10637-016-0371-6 
16. Schmid P, Adams S, Rugo HS, Schneeweiss A, Barrios $\mathrm{CH}$, Iwata H, Dieras V, Hegg R, Im SA, Shaw Wright G, Henschel V, Molinero L, Chui SY, Funke R, Husain A, Winer EP, Loi S, Emens LA, Investigators IMT (2018) Atezolizumab and Nabpaclitaxel in advanced triple-negative breast cancer. N Eng J Med 379(22):2108-2121. https://doi.org/10.1056/NEJMoa1809615

17. Yang J, Zhao H, Garnett C, Rahman A, Gobburu JV, Pierce W, Schechter G, Summers J, Keegan P, Booth B, Wang Y (2013) The combination of exposure-response and case-control analyses in regulatory decision making. J Clin Pharmacol 53(2):160-166. https://doi.org/10.1177/0091270012445206

18. Wang J, Song P, Schrieber S, Liu Q, Xu Q, Blumenthal G, Amiri Kordestani L, Cortazar P, Ibrahim A, Justice R, Wang Y, Tang S, Booth B, Mehrotra N, Rahman A (2014) Exposure-response relationship of T-DM1: insight into dose optimization for patients with HER2-positive metastatic breast cancer. Clin Pharmacol Ther 95(5):558-564. https://doi.org/10.1038/clpt.2014.24

19. Bajaj G, Wang X, Agrawal S, Gupta M, Roy A, Feng Y (2017) Model-based population pharmacokinetic analysis of nivolumab in patients with solid tumors. CPT Pharmacometrics Syst Pharmacol 6(1):58-66. https://doi.org/10.1002/psp4.12143

20. Li H, Yu J, Liu C, Liu J, Subramaniam S, Zhao H, Blumenthal GM, Turner DC, Li C, Ahamadi M, de Greef R, Chatterjee M, Kondic AG, Stone JA, Booth BP, Keegan P, Rahman A, Wang Y (2017) Time dependent pharmacokinetics of pembrolizumab in patients with solid tumor and its correlation with best overall response. J Pharmacokinet Pharmacodyn 44(5):403-414. https:// doi.org/10.1007/s10928-017-9528-y

21. Liu C, Yu J, Li H, Liu J, Xu Y, Song P, Liu Q, Zhao H, Xu J, Maher VE, Booth BP, Kim G, Rahman A, Wang Y (2017) Association of time-varying clearance of nivolumab with disease dynamics and its implications on exposure response analysis. Clin Pharmacol Ther 101(5):657-666. https://doi.org/10.1002/cpt.656

22. Wang Y, Booth B, Rahman A, Kim G, Huang SM, Zineh I (2017) Toward greater insights on pharmacokinetics and exposureresponse relationships for therapeutic biologics in oncology drug development. Clin Pharmacol Ther 101(5):582-584. https://doi. org/10.1002/cpt.628

23. Bruno R, Mercier F, Claret L (2014) Evaluation of tumor size response metrics to predict survival in oncology clinical trials. Clin Pharmacol Ther 95(4):386-393. https://doi.org/10.1038/ clpt.2014.4

24. Claret L, Jin JY, Ferte C, Winter H, Girish S, Stroh M, He P, Ballinger M, Sandler A, Joshi A, Rittmeyer A, Gandara D, Soria JC, Bruno R (2018) A model of overall survival predicts treatment outcomes with atezolizumab versus chemotherapy in non-small cell lung cancer based on early tumor kinetics. Clin
Cancer Res 24(14):3292-3298. https://doi.org/10.1158/10780432.CCR-17-3662

25. Bruno R, Claret L, Wu B, Jin JY, Winter H, Cui N, Derleth CL, Shen X, Girish S, Rosenberg JE, Powles T (2018) A tumor growth rate/overall survival model for atezolizumab as an early predictor of OS in patients with first or second line metastatic urothelial carcinoma. J Clin Oncol 36(5_Suppl):62. https://doi.org/10.1200/ jco.2018.36.5_suppl.62

26. Beal S, Sheiner LB, Boeckmann A, Bauer RJ (2011) NONMEM user's guides. (1989-2011). Icon Development Solutions, Ellicott City, MD

27. Center for drug evaluation and research. BLA (2016) 761034 clinical pharmacology review-atezolizumab. https://www.acces sdata.fda.gov/drugsatfda_docs/nda/2016/761034Orig1s000ClinP harmR.pdf. Accessed 14 May 2019

28. Hanauer SB, Wagner CL, Bala M, Mayer L, Travers S, Diamond RH, Olson A, Bao W, Rutgeerts P (2004) Incidence and importance of antibody responses to infliximab after maintenance or episodic treatment in Crohn's disease. Clin Gastroenterol Hepatol 2(7):542-553

29. Shankar G, Pendley C, Stein KE (2007) A risk-based bioanalytical strategy for the assessment of antibody immune responses against biological drugs. Nat Biotechnol 25(5):555-561. https:// doi.org/10.1038/nbt1303

30. KEYTRUDA (pembrolizumab) [summary of product characteristics.]. Merck Sharp \& Dohme B.V., Haarlem, The Netherlands, 2019

31. OPDIVO (nivolumab) [package insert]. Bristol-Meyers Squibb Company, Princeton, NJ, 2018

32. Lala M, Li M, Sinha V, de Alwis D, Chartash E, Jain L (2018) A six-weekly (Q6W) dosing schedule for pembrolizumab based on an exposure-response (E-R) evaluation using modeling and simulation. J Clin Oncol 36(15):3062

33. Zhao X, Suryawanshi S, Hruska M, Feng Y, Wang X, Shen J, Vezina HE, McHenry MB, Waxman IM, Achanta A, Bello A, Roy A, Agrawal S (2017) Assessment of nivolumab benefit-risk profile of a $240-\mathrm{mg}$ flat dose relative to a $3-\mathrm{mg} / \mathrm{kg}$ dosing regimen in patients with advanced tumors. Ann Oncol 28(8):2002-2008. https://doi.org/10.1093/annonc/mdx235

34. Freshwater T, Kondic A, Ahamadi M, Li CH, de Greef R, de Alwis D, Stone JA (2017) Evaluation of dosing strategy for pembrolizumab for oncology indications. J Immunother Cancer 5:43. https://doi.org/10.1186/s40425-017-0242-5

Publisher's Note Springer Nature remains neutral with regard to jurisdictional claims in published maps and institutional affiliations. 